\title{
Dose Rate Assessment at a Gamma Processing Facility in Ghana
}

\author{
T. A. Sackey * \\ Institute for Scientific and Technological Information, \\ Council for Scientific and Industrial Research, Accra, Ghana \\ G. K. Banini \\ Ghana Atomic Energy Commission, \\ Accra, Ghana \\ G. Emi-Reynolds \\ Nuclear Regulatory Authority, \\ Accra, Ghana \\ E. Gyasi \\ Radiation Protection Institute, GAEC, \\ Accra, Ghana
}

\begin{abstract}
This study was carried out to verify the adequacy of the shielding mechanisms in place at the Gamma Irradiation Facility (now Radiation Technology Centre) of the Ghana Atomic Energy Commission to ensure that workers of the facility are not over-exposed to radiation in routine work as prescribed by the local authority and international regulations. A category IV Wet Storage Gamma Irradiation Facility, Ghana Atomic Energy Commission, Accra Ghana. The duration of the study was six months. Use of Rad-Eye G-10 Thermo Scientific Gamma Survey Meter to measure dose rate around the biological shield of a Co-60 source (activity of $27.4 \mathrm{kCi}$, was in the irradiation position) at controlled areas of the facility, which included control room, electrical power room, deionizer room, the roof of irradiation chamber (specifically roof plugs) and two entrances to the irradiation chamber (the personnel door and the goods door). Background reading was $0.08 \pm 0.01 \mu \mathrm{Sv} / \mathrm{h}$. Radiation dose rates at the Personnel door and the goods door were $0.090 \mu \mathrm{Sv} / \mathrm{h}$ and $0.109 \mu \mathrm{Sv} / \mathrm{h}$, respectively. Practical measurements at the roof plugs produced average values of $0.135 \mu \mathrm{Sv} / \mathrm{h}$. A particular point on Plug-3 produced a relatively higher reading of $8.151 \mu \mathrm{Sv} / \mathrm{h}$. Measurements in the control room, electrical room, and deionizer room gave average readings of $0.116 \mu \mathrm{Sv} / \mathrm{h}, 0.089 \mu \mathrm{Sv} / \mathrm{h}$, and $0.614 \mu \mathrm{Sv} / \mathrm{h}$, respectively. All average values were below the limits of $7.5 \mu \mathrm{Sv} / \mathrm{h}$ and $50 \mathrm{mSv} / \mathrm{yr}$. Total radiation at the entrances of the mazes is due mainly to scattered radiation. The shielding by lead doors $(0.009 \mathrm{~m})$ and concrete walls $(1.6 \mathrm{~m}-1.9 \mathrm{~m})$ of the installed $1.85 \mathrm{PBq}(50 \mathrm{kCi})$ rectangular plaque Co-60 source irradiation chamber are sufficient to shield occupationally exposed workers at the facility when the source is in the storage position and operation. The dose limit of $7.5 \mu \mathrm{Sv} / \mathrm{h}$ (i.e., $50 \mathrm{mSv}$ per year) is not exceeded. The presence of an entrance maze $(8.1 \mathrm{~m}$ and $9.1 \mathrm{~m})$ is also adequate and contributes to multiple scattering. The visual and audio warning mechanisms and interlock systems are satisfactory and adequate, provided the facility is operated safely to prevent over-exposure. Shielding calculations (in particular for the deionizer room) would need to be carried out before such an upgrade to a 500kCi source.
\end{abstract}

Keywords: Radionuclides, monitoring, irradiation, gamma, shielding

Received: 20 October 2019; Accepted: 01 January 2020; Published: 25 March 2020

\section{INTRODUCTION}

Gamma irradiation technology is based on a radioactive Cobalt-60 source [1]. Gamma irradiation facilities use extremely high doses of radiation to achieve their required results. Construction and shielding of such a facility should ensure that workers are not overly exposed to radiation during normal operation and maintenance and that there is insignificant public exposure [2]. Shielding materials can be made up of water, concrete, and dense metals such as lead and tungsten [3].

Gamma Irradiation Laboratory is mostly used for several applications like enhancing or altering molecular

\footnotetext{
${ }^{*}$ Correspondence concerning this article should be addressed to T. A. Sackey, Institute for Scientific and Technological Information, Council for Scientific and Industrial Research, Accra, Ghana. E-mail: tracyadjeleysackey@gmail.com

(c) 2020 The Author(s). Published by KKG Publications. This is an Open Access article distributed under a Creative Commons AttributionNonCommercial-NoDerivatives 4.0 International License.
} 
structure and other properties of polymers [4], altering gemstone color [5], and others.

At the Radiation Technology Centre (RTC), Ghana Atomic Energy Commission (GAEC), gamma radiation is used to process crops and foodstuffs mainly for export and to sterilize medical equipment such as syringes intravenous infusions, and gauzes without destruction of their packages [6]. The primary shielding of the source when not in use is a pool of water at a depth of $5.7 \mathrm{~m}$. Concrete walls and lead doors make up the barriers of the irradiation chamber. Radiation monitoring comprises of measurement of radiation levels, concentration of radioactive material, and the use of the produced results to evaluate potential exposures and doses [7] International Commission on Radiological Protection and Units [8] gives the conditions for conducting either workplace or individual monitoring; any person who normally or occasionally works in a controlled area in a radiation practice and may receive significant exposure shall be provided individual monitoring where appropriate, adequate and feasible. Where individual monitoring is inappropriate, inadequate or not feasible, occupational monitoring shall be based on workplace monitoring and information about locations and durations of worker exposure. Workplace monitoring takes into consideration external dose rate and contamination whiles individual monitoring measures accumulative individual doses. Previous monitoring conducted at the facility occurred when the facility was loaded with 1.85 $\mathrm{PBq}(50 \mathrm{kCi}) \mathrm{Co}-60$ source in a cylindrical configuration. Measurements were taken within the maze entrances and outside the lead doors, in the control, electrical and deionizer room using a Chinese made dose rate survey meter model SG-102 [9]. Theoretical calculations of dose rates since the change of source have been carried out by Emi-Reynolds \& Akaho [10] using the ANISN code and by Fletcher et al [11]. Practical measurements have also been carried out by Thembinkosi [12] using ThermoLuminescent Dosimeters (TLD), Ethanol-Chlorobenzene (ECB) and Fricke dosimeters.

The initial cylindrical source was changed to a rectangular plaque source configuration with an activity of approximately $1.85 \mathrm{PBq}(50 \mathrm{kCi})$ when installed in August 2010. This change was meant to upgrade the facility for economical radiation processing. Secondly to improve on the uniformity ratio of gamma processed goods. Theoretical calculations were made prior to the installation of the rectangular plaque source to predict dose rates at various sections of the facility. Shape, orientation and position of a source have an impact on dose rates. International Commission on Radiological Protection (ICRP) recommends the cumulative dose limit of $20 \mathrm{mSv} / \mathrm{y}$ averaged over five years for occupationally exposed workers and 1 $\mathrm{mSv} / \mathrm{y}$ members of the public [13].

One of the objectives of the present study is to demonstrate that personnel dose rates in controlled and supervised areas do not exceed the dose limit of $20 \mathrm{mSv}$ per year as established by regulations. In this research workplace monitoring was carried out to determine various dose rates at different areas in the vicinity to ascertain safety of personnel. The current work focused on a more detailed study of the facility and measurements have been compared with previous theoretically obtained values.

Technical structures at RTC were designed to permit a maximum loading capacity of a source with an activity of $18.5 \mathrm{PBq}(500 \mathrm{kCi})$. Activity and dose rate share a positive linear relationship, any plans for an increase in activity implies that computations must be made to certify that shielding of the irradiation chamber is sufficient to cater for the upgrade. This study therefore performed experimental measurements to verify that doses that would be received by personnel operating and maintaining the performance of the facility using the $1.85 \mathrm{PBq}(50 \mathrm{kCi})$ rectangular plaque source were within acceptable limits.

\section{MATERIALS AND METHOD}

\section{A. Materials}

A calibrated Rad-Eye G-10 Survey Meter with dimensions $3.1 \mathrm{~cm} \times 6.1 \mathrm{~cm} \times 9.6 \mathrm{~cm}$ was used in taking dose rate measurements. It is a digital, highly sensitive, very portable and robust machine that produces quick and reliable dose rate measurements from $0.5 \mu \mathrm{Sv} / \mathrm{h}$ up to $100 \mathrm{mSv} / \mathrm{h}$. It contains a Geiger Muller Tube (GMT) which detects gamma and $\mathrm{x}$ - rays in the energy range of $50 \mathrm{keV}$ to $3 \mathrm{MeV}$. It has vibrating, visual and audible alarms.

The stainless steel rectangular source rack has 4 modules or compartments. Each module has 17 active source pencils of varying activities arranged on it amounting to 68 source pencils with a total manufacturing activity of $1.88 \mathrm{PBq}(50.9 \mathrm{kCi})$, an installation activity as at August 2010 of $1.84 \mathrm{PBq}(49.7 \mathrm{kCi})$ and activity as at March 2015 of $1.014 \mathrm{PBq}(28 \mathrm{kCi})$.

\section{B. Methods}

1) Dose rate measurements: Personnel and goods doors - Measurements were taken at the two entrances of the Irradiation chamber, the personnel door and the goods entrance door. The personnel door was divided into columns labelled A to E and rows numbered 1 to 7 as in Fig. 1. Measurements of dose rates were repeated 5 times and then averaged at that point. Similarly, the goods door was divided into columns labelled $\mathrm{A}$ to $\mathrm{C}$ and rows numbered 
1 to 5 as in Fig. 2. Measurements of dose rates were taken within the maze entrances and outside the lead doors, in the control room, electrical and deionizer rooms similar to that above.

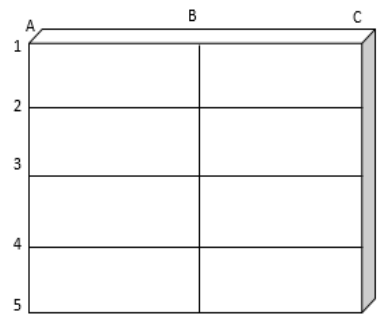

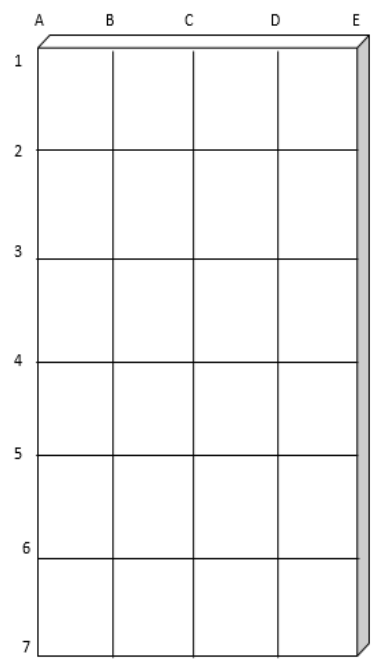

Fig. 1. (a) Lead personnel door (thickness $=9 \mathrm{~mm}$ ) (b). Lead goods door

Roof plug measurements - Measurements were taken at the five roof plugs of the irradiation chamber. They are slots that hold in place the hoist mechanism of the source. They were labelled P1 to P5 as shown in Fig. 2.
Measurements at each plug were each taken five times and recorded. They were averaged to obtain the dose rate at each plug.

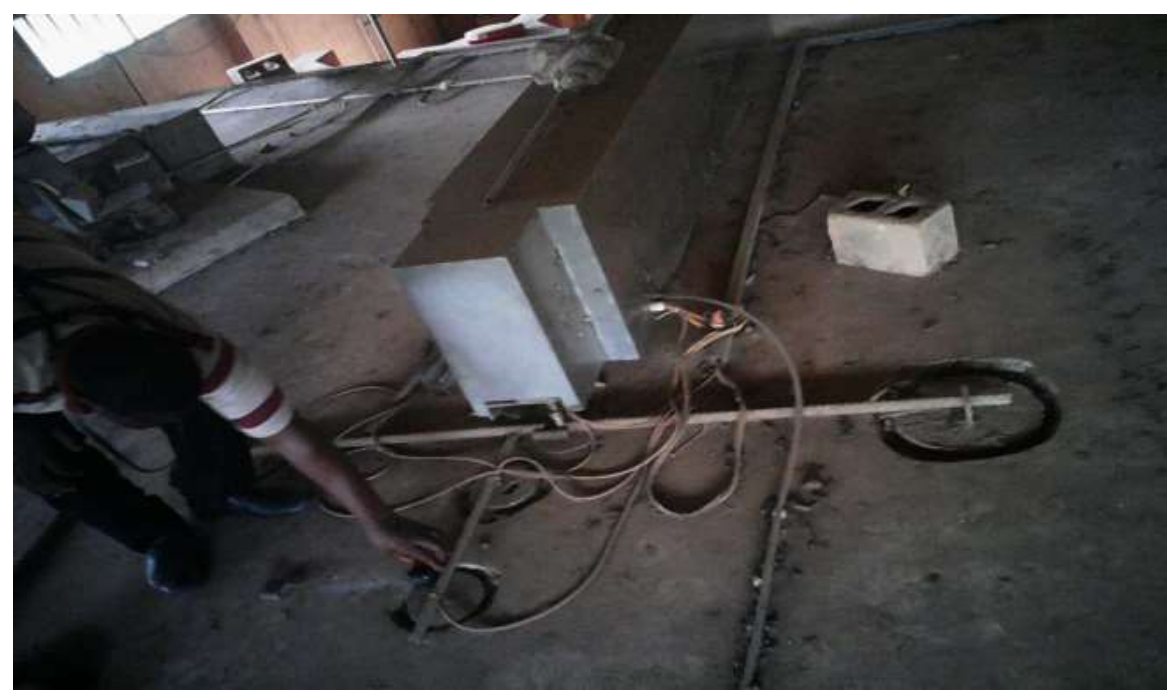

Fig. 2. Roof of irradiation chamber showing roof plugs

Controlled area measurements - The control room, electric room (Fig. 3) and deionizer room (Fig. 4) make up the controlled rooms and are the rooms closest to the irradiation chamber that are usually occupied or used by personnel. Measurements were taken likewise five times at strategic points in each room which share a wall with the irradiation chamber. Such points had openings to allow penetration of pipes and wiring and were prone to a relatively higher radiation dose rate measurement. 


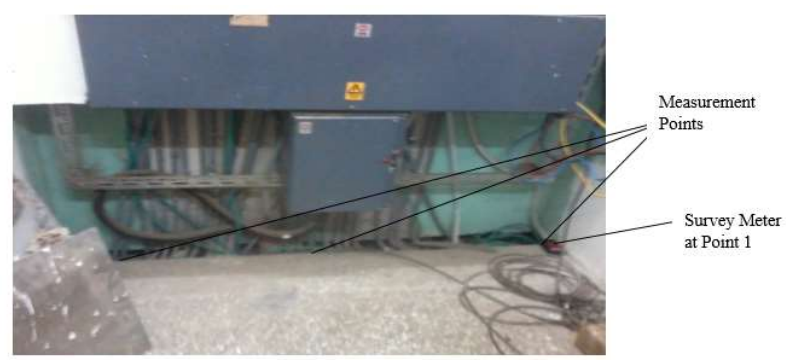

Fig. 3. Electric room showing measurement points

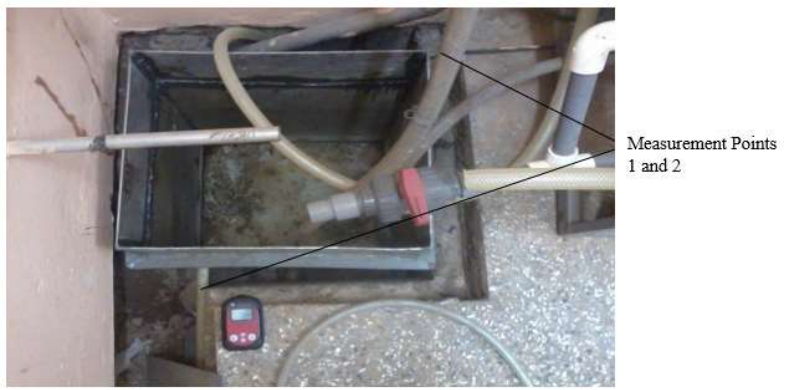

Fig. 4. Deionizer room showing measurement points 1 and 2 of the inlet tank that connects to the irradiation chamber through the concrete walls

Extrapolations for a $500 \mathrm{kCi}$ source - An extrapolation using the current activity of the source for a source of $500 \mathrm{kCi}$ required multiplying values measured and com- puted by a factor of 18.25 to cater for the increment as shown in Equation 1.

$$
D_{500}=(500 / 27.4) \times D_{27.4}=18.25 \times \mathrm{D}_{27.4}
$$

\section{RESULTS AND DISCUSSION}

\section{A. Personnel and Goods Doors}

Average background measurement at the entrance of the facility when the source was down and in the absence of any radioactive material was recorded as $0.090 \pm 0.022$ $\mu \mathrm{Sv} / \mathrm{h}$. Measurements made at the personnel door produced an average dose rate of $0.098 \mu \mathrm{Sv} / \mathrm{h}$. A value of $0.026 \mu \mathrm{Sv} / \mathrm{h}$ (position B5) and a maximum value of 0.130 $\mu \mathrm{Sv} / \mathrm{h}$ (position A3) which is adjacent to the Co-60 test source embedded in the wall (Fig. 5) used to check radiation monitor before entering the irradiation chamber. The average dose rate value recorded implies that for a worker operating 8hours a day, 5 times a week for 50 weeks a year, a yearly dose rate of $0.196 \mathrm{mSv}$. Most recorded dose rate values were close to background readings, indication that adequate shielding is in place for personnel and goods door.

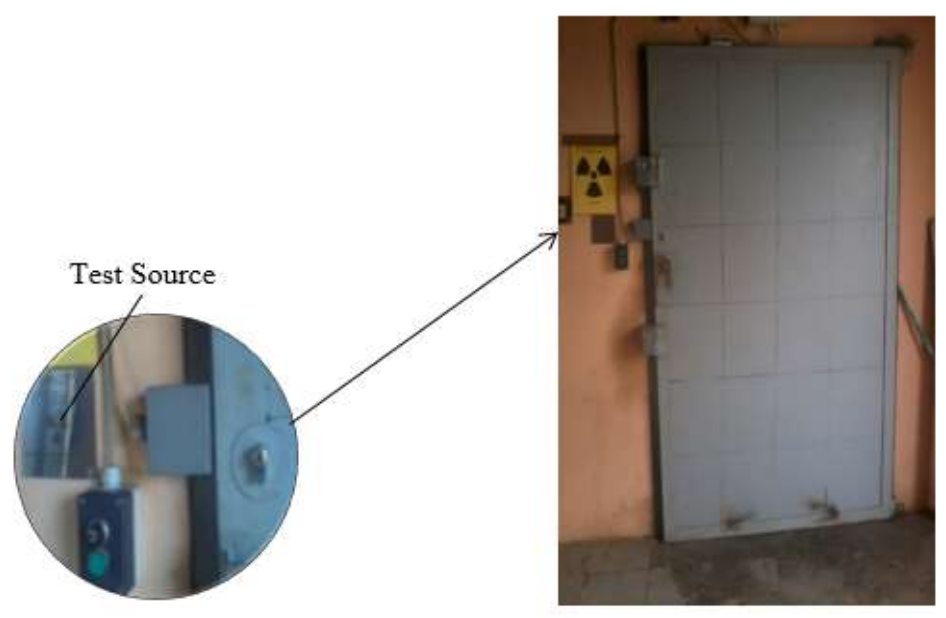

Fig. 5. Personnel door showing position of test source relative to door position A3

\section{B. Control, Electric and Deionizer Room}

Dose rates in the controlled areas which included the control room, electric room and deionizer room, the average dose rates obtained were $0.100 \mu \mathrm{Sv} / \mathrm{h}, 0.080 \mu \mathrm{Sv} / \mathrm{h}$ and $0.504 \mu \mathrm{Sv} / \mathrm{h}$. These rooms directly share a wall with the irradiation chamber. The higher reading in the deionizer room when source was in the unshielded position may be attributed to leakage of radiation around conduit pipes that take de-ionised water from recycling to the irradiation tank through the walls. This means that although personnel who may be occupying and working in these rooms are safe and are not over exposed, however their movement should be restricted in the deionizer room in order to further reduce their exposure.

\section{Roof Plugs}

Dose rate at roof plugs 1 to 5 when source is unshielded gave an average reading of $0.120 \mu \mathrm{Sv} / \mathrm{h}$ equivalent to yearly dose of $0.24 \mathrm{mSv}$. A particular area shown in Fig. 6 however recorded a relatively high reading of $7.150 \mu \mathrm{Sv} / \mathrm{h}$. This observation may be due to inadequate shielding at that particular area due to radiation leak- 
age. Although, staff visit to the roof is only allowed for cleaning and maintenance work when the source is fully shielded, it is recommended that the orifices around the roof plugs be sealed with concrete or a mixture of concrete and lead shot to further reduce the dose rate when the facility is in operation.

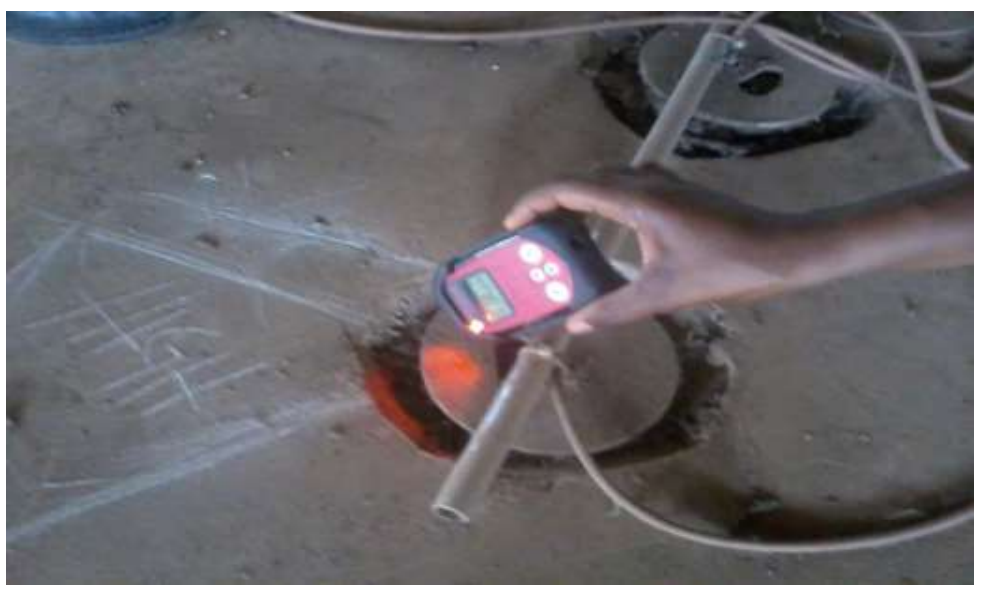

Fig. 6. Gamma survey meter recording value at "high point" of roof plug 3

\section{Comparison of Practical Results}

Previous results obtained by Emi-Reynolds et al. [4] and Thembinkosi [7] were scaled to present activity for the facility and compared to measurements taken. The results are presented in Table 1.

TABLE 1

COMPARISON OF DOSE RATES WITH OTHER STUDIES

\begin{tabular}{llll}
\hline \multirow{2}{*}{ Position } & \multicolumn{3}{c}{ Dose Rates $(\mu \mathrm{Sv} / \mathrm{h})$} \\
\cline { 2 - 4 } & Emi-Reynolds et al. [4] @ 27.4kCi & Thembinkosi [7], @ 27.4kCi & Present Study \\
\hline Personnel Door & 0.215 & 0.058 & 0.098 \\
Goods Door & 0.213 & 0.036 & 0.152 \\
Control Room & 0.006 & 0.036 & 0.100 \\
Electric Room & $<0.01$ & 0.050 & 0.080 \\
Deionizer Room & $<0.003$ & 3.035 & 0.504 \\
Roof & 0.164 & 0.050 & 0.120 \\
\hline
\end{tabular}

Values of dose rates for the doors and roof were all higher during the use of the cylindrical source than that of the current rectangular source. This may be attributed to the fact that the current dimensions of the source reduce dose rates to the specified locations. Thembinkosi's values are lower with the exception of the dose rates at the deionizer room. This may be due to a difference in actual measurement points in the room. Her value at the goods door was also much lower and it may be assumed that it was taken at chest level which would coincide with row 1 of the goods door. Values at that location were comparable.

\section{E. Extrapolation for $500 \mathrm{kCi}$}

Dose rates were predicted for a $500 \mathrm{kCi}$ source in specified areas of the facility based on practical results as listed in Table 2.

Practically, results show that the deionizer room maybe potentially unsafe if an upgraded $500 \mathrm{kCi}$ source is installed without increasing the shield thickness. The location of high dose rate corresponds in actual fact to the area around the pipe interconnection between the deionizer room and the adjourning pool in tank in the irradiation chamber. A practical way of reducing this dose rate is to increase the scattering by introduction of lead shots. This is because limit of $7.5 \mu \mathrm{Sv} / \mathrm{h}$ was exceeded in this vicinity alone except that the occupancy of this location may never go beyond $1 / 4$. 
TABLE 2

PREDICTED DOSE RATES FOR A 500KCI SOURCE

\begin{tabular}{ll} 
Location & Extrapolated Dose Rates $(\mu \mathrm{Sv} / \mathrm{hr})$ \\
\hline & \\
Personnel Door & 1.79 \\
Goods Door & 2.77 \\
Roof & 2.19 \\
Deionizer Room & 9.85 \\
\hline
\end{tabular}

\section{CONCLUSION}

Total radiation at the entrances of the mazes are due mainly to scattered radiations from the chamber when the sources are in the unshielded/working position. The shielding by lead doors $(0.009 \mathrm{~m})$ and concrete walls $(1.6 \mathrm{~m}-1.9 \mathrm{~m})$ of the installed $1.85 \mathrm{PBq}(50 \mathrm{kCi})$ rectangular plaque Co-60 source irradiation chamber are sufficient to ensure that for the current source, occupationally exposed workers are not over exposed and do not exceed the limits of $7.5 \mu \mathrm{Sv} / \mathrm{h}$ (ie. $50 \mathrm{mSv}$ per year) when the source is in operation. The presence of the maze design of $8.1 \mathrm{~m}$ (personnel entrance) and $9.1 \mathrm{~m}$ (goods entrance) is adequate and contributes to the low value measured due to multiple scatter. There may however be concerns with upgrading the source strength to $500 \mathrm{kCi}$ source and further measurements and calculations of shielding (in particular for the deionizer room) would need to be carried out before such an upgrade. This work demonstrates that the shielding is effective in protecting staff at the facility provided that the laid down protocols are followed by staff.

Though measurements were relatively low, further precautions can be taken by clogging entrances of openings in the electrical and deionizer rooms through which the wiring and pipes are passed with lead shots. This would further scatter radiation from the cavities and reduce what is being transmitted into those rooms.

Considering the category of the irradiation facility (category IV), the ISO standard 21482 (ionizing radiation supplementary symbol) should be placed on the source rack in addition to the Trefoil at the entrance of the irradiation chamber.

It is also recommended that for further studies, a 3-D mapping of accumulative dose rates in the control, electric and deionizer room be conducted to obtain contours of dose rates at all positions in the rooms. This would reveal any cracks in the concrete shielding.

\section{ACKNOWLEDGEMENT}

Many thanks to the Manager, Radiation Technology Centre, Ghana Atomic Energy Commission, for granting access to the facility and to the workers for their assis- tance.

\section{REFERENCES}

[1] P. Dethier, "Industrial gamma and x-ray: "Same but different",' Louvain-la-Neuve, Belgium: Ion Beam Applications (IBA), White paper, 2016. [Online]. Available: https://bit.ly/3BJlSpL

[2] IAEA-1454, Radiation Safety of Gamma, Electron and X-Ray Irradiation Facilities. Vienna, Austria: International Atomic Energy Agency, 2010.

[3] Thomas. (2015) Materials used in radiation shielding. [Online]. Available: https://bit.ly/2WP8fpC

[4] A. S. Medeiros, M. R. Gual, C. Pereira, and L. O. Faria, "Thermal analysis for study of the gamma radiation effects in poly (vinylidene fluoride)," Radiation Physics and Chemistry, vol. 116, pp. 345-348, 2015. doi: https://doi.org/10.1016/j.radphyschem. 2015.05.006

[5] H. Silva and M. FS, "Beryl colorless, quartz, and brazilianita study using x-ray diffraction, spectroscopy in the infrared region and gamma irradiation in," in Proceedings of the Semana de Engenharia Nuclear e Ciências das Radiaçoes (Sencir), Portuguese, 2014.

[6] A. Adu-Gyamfi, "Safety analysis report." Radiation Technology Centre, Accra, Ghana, Tech. Rep., 2011.

[7] Stanford University, Radiation Safety Manual. Stanford, CA: Stanford University, 2015.

[8] C. Cousins, D. Miller, G. Bernardi, M. Rehani, P. Schofield, E. Vañó, A. Einstein, B. Geiger, P. Heintz, R. Padovani et al., "International commission on radiological protection," ICRP Publication, vol. 120, pp. 1-125, 2011.

[9] G. Emi-Reynolds, G. Banini, and E. H. Akaho, "Practical evaluation of the biological shielding effectiveness of the gamma irradiation facility at Kwabenya, Ghana," Ghana Atomic Energy Commission, Accra, Ghana, Tech. Rep., 1997.

[10] G. Emi-Reynolds and E. H. Akaho, "A theoretical evaluation of the effectiveness of the biological 
shields for the 0.5 MCi irradiation facility," Journal of the Kumasi University of Science and Technology, vol. 14, no. 2, pp. 79-89, 1994.

[11] J. Fletcher, G. Emi-Reynolds, and E. Glover, "Shielding calculations for changing from circular to a rectangular source configuration for a pilot scale irradiator," Journal of Applied Science and Technology, vol. 5, no. 1, pp. 39-44, 2000.
[12] T. E. Mavuso, "Experimental evaluation of the biological shielding effects of the upgraded gamma irradiation facility," University of Ghana, LegonAccra, Ghana, Master thesis, 2013.

[13] I. Publ, "2007 recommendations of the international commission on radiological protection," Annals of the ICRP, vol. 37, pp. 2-4, 2008. 